\title{
PENGARUH PENYIMPANAN DAN WAKTU PENETASAN TELUR TERHADAP KUALITAS BIBIT ULAT SUTRA DAN KUALITAS KOKON Bombyx mori L.
}

\author{
(The Effect of Egg Preservation and Hatching Schedule on Seed Quality and Cocoon \\ Quality of Silkworm Bombyx mori L.) \\ Lincah Andadari ${ }^{1}$ dan/and Kuntadi $^{2}$ \\ ${ }^{1}$ Pusat Penelitian dan Pengembangan Hutan \\ J1. Gunung Batu No. 5 Po Box 165 Bogor, Jawa Barat, Indonesia \\ Telp. 0251-8633234; Fax 0251-8638111 \\ ${ }^{2}$ Perhimpunan Entomologi Indonesia \\ E-mail: a.lincah@yahoo.co.id
}

Tanggal diterima: 7 November 2017; Tanggal direvisi: 10 Mei 2019; Tanggal disetujui; 15 Mei 2019

\begin{abstract}
Silkworm eggs are a key factor in sericulture industry. Good quality of silkworm eggs cannot be produced any times. Therefore eggs preservation techniques becoming the most important aspect to be handled. Storage trial of Bombyx mori L. silkworm eggs through one cooling stage at $5{ }^{\circ} \mathrm{C}$ was carried out to obtain appropriate preservation techniques for longterm period. A factorial experiment based on randomized block design was performed to study the egg preservation and hatching techniques of 2 silkworm races. The results showed that cold storage duration affected incubation period and hatching uniformity. High hatching percentage (>90\%) was produced by eggs preservation at $25{ }^{\circ} \mathrm{C}$ for 1 day followed by cold storage $\left(5^{\circ} \mathrm{C}\right.$ ) for 69 days, then treated with $\mathrm{HCl}$ of 1.094 specific gravity at $48{ }^{\circ} \mathrm{C}$ for 7 minutes. The duration of cold storage affected the hatching percentage, but did not affect the quality of caterpillars and cocoon productions. Silkworm hybrid produced higher quality cocoon compare to pure strain. Eggs preservation at room temperature $\left(25^{\circ} \mathrm{C}\right)$ for 10 days followed by refrigeration at $5^{\circ} \mathrm{C}$ for 60 days produced better quality of eggs and cocoons.
\end{abstract}

Keywords: hatching technique, production, sericulture

\begin{abstract}
ABSTRAK
Bibit telur ulat sutra merupakan faktor kunci di dalam industri persutraan alam. Bibit ulat sutra bermutu baik tidak dapat diproduksi setiap saat sepanjang waktu. Oleh sebab itu teknik penyimpanan telur menjadi aspek penting yang harus dikuasai agar mampu menyediakan bibit berkualitas sepanjang waktu sesuai kebutuhan. Uji coba penyimpanan telur ulat sutra Bombyx mori L. melalui satu tahap pendinginan pada suhu $5^{\circ} \mathrm{C}$ telah dilakukan dengan tujuan mendapatkan teknik penyimpanan yang sesuai untuk tetap menjaga kualitas dan produktivitas bibit dalam jangka panjang. Percobaan faktorial dalam rancangan acak kelompok digunakan untuk menguji mutu bibit ulat sutra melalui teknik penyimpanan dan penetasan telur dari dua galur ulat sutra. Hasil penelitian menunjukkan lama penyimpanan dingin berpengaruh terhadap lama waktu inkubasi dan keserempakan penetasan. Persentase penetasan yang tinggi $(>90 \%)$ dihasilkan oleh telur yang telah melalui penyimpanan pada suhu $25^{\circ} \mathrm{C}$ selama 1 hari dan penyimpanan dingin $\left(5^{\circ} \mathrm{C}\right)$ selama 69 hari, kemudian diberi perlakuan asam $\mathrm{HCl}$ dengan berat jenis 1,094 pada temperatur $48^{\circ} \mathrm{C}$ selama 7 menit. Lama penyimpanan dingin hanya memengaruhi persentase penetasan, tetapi tidak berpengaruh terhadap mutu ulat dan kokon. Ulat sutra galur hibrid menunjukkan hasil yang lebih tinggi dibandingkan dengan galur murni. Penyimpanan pada $25^{\circ} \mathrm{C}$ selama 10 hari dan dilanjutkan pada suhu $5^{\circ} \mathrm{C}$ selama 60 hari menghasilkan kualitas telur dan kokon yang lebih bagus.
\end{abstract}

Kata kunci: produksi, persutraan, teknik penetasan

\section{PENDAHULUAN}

Kualitas kokon yang baik merupakan target utama di dalam usaha pemeliharaan ulat sutra, karena akan menentukan kualitas benang yang dihasilkan. Kualitas kokon ditentukan oleh beberapa faktor antara lain sifat keturunan, jenis ulat sutra, keadaan 
selama pemeliharaan, waktu pemindahan ulat pada alat pengokonan, lingkungan dan kualitas pakan, serta metode pemberian pakan ulat sutra. Kualitas bibit merupakan aspek penting dalam industri persutraan alam (Sarkar, Sarmah, Dutta, \& Dutta, 2012). Kehilangan produksi atau kegagalan usaha budidaya ulat sutra dapat disebabkan oleh kualitas bibit yang rendah. Oleh karena itu, perbaikan teknik pembibitan harus terus diupayakan.

Kelola pembibitan bertujuan untuk memproduksi bibit berkualitas baik secara efisien dan ekonomis. Di daerah tropis, produksi bibit hanya dilakukan pada kondisi musim yang optimum, meskipun pemeliharaan ulat dapat berlangsung sepanjang tahun (Sarkar et al., 2012). Kondisi disebut optimum ketika pemeliharaan dapat menghasilkan pupa hidup yang tinggi dan telur yang banyak. Hal ini disebabkan oleh pengaruh faktor lingkungan yang sangat tinggi terhadap kehidupan dan produktivitas ulat sutra (Hemmatabadi, Seidavi, \& Gharahveysi, 2016; Rahmathulla, 2012). Untuk itu, pemanfaatan telur diatur dengan mengaplikasikan teknik penyimpanan dan penetasan yang tepat sehingga bibit dapat tersedia setiap saat untuk memenuhi kebutuhan petani pelaku budidaya dengan kualitas yang tetap terjaga. Penyimpanan telur dilakukan pada saat embrio memasuki masa dorman (diapause), baik yang terjadi secara alami (Kumaresan, Thangavelu, \& Sinha, 2004) maupun melalui perlakuan tertentu (Jingade, Babu, Lekha, Nair, Rao, \& Manjula, 2013; Rajanna, Raju, Prabhakar, \& Kamble, 2008).

Ulat sutra secara genetik memiliki 2 karakter, yaitu jenis yang secara alami mengalami dormansi pada fase telur dan jenis yang tidak mengalami dormansi (non-diapause). Diapause merupakan ekspresi organisme yang ditentukan oleh faktor genetik dan mekanisme endokrinologi sebagai respon terhadap stimulus kondisi lingkungan (Tribhuwan
Singh, Singh, \& Sahaf, 2013). Pada ulat sutra, diapause terjadi dalam proses embriogenesis pada saat pembelahan sel embrio memasuki tingkat gastrula (Yamamoto, Mase, \& Sawada, 2013). Secara umum, proses terjadinya diapause dipicu oleh faktor lingkungan (suhu, kelembaban, dan fotoperiodisme) yang tidak kondusif bagi perkembangan embrio (Kumar \& Ponnuvel, 2007). Proses sebaliknya akan terjadi pada saat kondisi lingkungan berubah menguntungkan, yaitu kondisi diapause akan berakhir dan proses perkembangan akan berjalan kembali. Pada jenis non-diapause, dormansi embrio dapat dipicu oleh adanya efek kejut akibat perendaman telur pada zat asam seperti $\mathrm{HCl}$ (Rajanna et al., 2008) atau penyimpanan pada suhu rendah (Kumaresan et al., 2004). Efek kejut yang sama dapat menghasilkan fungsi sebaliknya, yakni menghentikan proses diapause dan mengaktifkan kembali perkembangan embrio dari kondisi dorman (Abdelmegeed, 2016; Yamamoto et al., 2013). Pada ulat sutra diapause terjadi pada fase embrio, sehingga umur dan daya simpan telur ulat sutra tergantung pada jangka waktu lamanya fase dormansi (embryonic diapause). Pengaturan kondisi lingkungan tersebut dapat menjadi penentu umur simpan telur.

Daya simpan dan metode penyimpanan telur ulat sutra sudah dipelajari sejak lama dengan tujuan agar mampu menyediakan kebutuhan bibit, baik jangka pendek maupun panjang. Penyimpanan telur pada suhu rendah terbukti dapat memperpanjang waktu dormansi sehinga dapat menunda proses penetasan sampai dengan jangka waktu yang dibutuhkan (Muthulakshmi \& Kamble, 2015). Meskipun demikian, daya simpan telur pada suhu rendah tingkat keamanannya sangat tergantung pada kondisi embrio, dan perkembangan embrio membutuhkan kondisi lingkungan fisiologis yang tepat untuk menjaga agar ulat yang akan lahir tetap memiliki daya 


\section{Pengaruh Penyimpanan dan Waktu Penetasan Telur Terhadap Kualitas Bibit Ulat Sutra dan Kualitas Kokon Bombyx Mori L.}

Lincah Andadari dan Kuntadi

tumbuh (viabilitas) yang baik (Rajanna $e t$ al., 2008). Oleh sebab itu, metode penyimpanan telur yang paling sedikit memengaruhi kualitas dan viabilitas bibit merupakan faktor penting dalam budidaya ulat sutra karena kondisi lingkungan penyimpanan secara langsung berpengaruh pada tingkat penetasan, perkembangan ulat, dan kualitas benang yang akan dihasilkan (Singh \& Saratchandra, 2004).

Prosedur penyimpanan dan penetasan (penghentian masa dormansi) telur secara umum ditentukan oleh kebutuhan lama penyimpanan. Tahapan yang harus dilalui dalam proses penyimpanan telur berbeda-beda untuk kebutuhan penetasan jangka pendek, menengah, dan panjang (Singh \& Saratchandra, 2004). Penyimpanan telur untuk jangka waktu tertentu, misalnya jadwal penetasan di atas 60 hari, harus dilakukan pendinginan pada suhu rendah melalui dua tahap (double step refrigeration), yaitu $5^{\circ} \mathrm{C}$ dan $2,5^{\circ} \mathrm{C}$. Prosedur yang dilalui sejak telur dihasilkan (oviposition) adalah 40-50 hari pada suhu $25^{\circ} \mathrm{C}, 6$ jam pada suhu $15^{\circ} \mathrm{C}$ pendinginan selama 40 hari pada suhu 5 ${ }^{\circ} \mathrm{C}$, pendinginan selama $20-30$ hari pada suhu $2,5^{\circ} \mathrm{C}$, perendaman dengan larutan asam $\mathrm{HCl}$ pada suhu $15^{\circ} \mathrm{C}$ dan inkubasi selama 5-6 menit pada suhu $48^{\circ} \mathrm{C}$ (Singh \& Saratchandra, 2004). Penelitian Rajanna et al. (2008) menunjukkan metode dua tahap pendinginan mampu menghasilkan daya tetas telur yang lebih tinggi daripada metode pendinginan tunggal (single step refrigeration), khususnya untuk jadwal penyimpanan jangka panjang, yaitu 60 dan 80 hari.

Tahap pendinginan menjadi masalah bagi laboratorium yang tidak dilengkapi cold storage dengan level pendinginan yang memadai. Untuk mengatasi persoalan tersebut, telah dilakukan uji coba penyimpanan telur menggunakan metode satu tahap pendinginan (single step refrigeration) dengan menghilangkan prosedur pendinginan pada suhu $2,5^{\circ} \mathrm{C}$ Penelitian dilakukan melalui eksperimen dengan perlakuan lama waktu pendinginan untuk jangka waktu penyimpanan 70 hari. Tujuan penelitian adalah untuk menguji penyimpanan telur ulat sutra Bombyx mori L. melalui satu tahap pendinginan pada suhu $5^{\circ} \mathrm{C}$ agar mendapatkan teknik penyimpanan yang sesuai untuk tetap menjaga kualitas dan produktivitas bibit.

\section{METODOLOGI}

\section{A. Tempat Penelitian}

Penelitian dilakukan di Laboratorium Persutraan Alam, Pusat Penelitian dan Pengembangan Hutan (P3H), Badan Penelitian, Pengembangan, dan Inovasi Kementerian Lingkungan Hidup dan Kehutanan, di Bogor.

\section{B. Metode}

\section{Rancangan percobaan}

Rancangan yang digunakan adalah Rancangan Acak Kelompok pola faktorial dengan faktor pertama (A) berupa dua galur ulat sutra Bombyx mori dan faktor kedua (B) adalah empat tata waktu penyimpanan telur yang dibagi menjadi empat kelompok. Galur ulat sutra terdiri dari galur murni 804 (A1) dan hibrid 8483 (A2). Galur murni 804 merupakan salah satu galur murni terbaik koleksi Bank Plasma $\mathrm{P} 3 \mathrm{H}$ yang dipakai sebagai indukan hibrid. Adapun hibrid 8483 merupakan hasil persilangan galur murni 804 dengan galur murni 803 . Tata waktu penyimpanan telur terdiri dari:

B1: Disimpan selama 1 hari pada suhu ruang $25^{\circ} \mathrm{C}+$ di refrigerator selama 69 hari pada suhu $5^{\circ} \mathrm{C}$

B2: Disimpan selama 10 hari pada suhu ruang $25^{\circ} \mathrm{C}+$ di refrigerator selama 60 hari pada suhu $5^{\circ} \mathrm{C}$ 
B3: Disimpan selama 20 hari pada suhu ruang $25^{\circ} \mathrm{C}+$ di refrigerator selama 50 hari pada suhu $5^{\circ} \mathrm{C}$

B4: Disimpan selama 40 hari pada suhu ruang $25^{\circ} \mathrm{C}+$ di refrigerator selama 30 hari pada suhu $5^{\circ} \mathrm{C}$

Masing-masing penyimpanan semua perlakuan memiliki jangka waktu yang sama yaitu 70 hari.

\section{Cara kerja}

Telur yang baru dihasilkan (oviposition) disimpan pada kondisi suhu ruang $\left(25^{\circ} \mathrm{C}\right)$ sesuai masing-masing perlakuan (yaitu selama 1, 10, 20, dan 40 hari), kemudian dimasukkan ke dalam cold storage untuk penyimpanan dingin pada suhu $5^{\circ} \mathrm{C}$ dalam waktu yang berlainan $(69,60,50$, dan 30 hari). Masing-masing perlakuan menggunakan 200 butir telur sebagai unit percobaan. Setelah penyimpanan dingin, telur dipindahkan kembali ke dalam ruangan dengan temperatur $25^{\circ} \mathrm{C}$ selama 3 jam lalu dicelupkan ke dalam $\mathrm{HCl}$ dengan berat jenis (BJ) 1,094 dan temperatur $48^{\circ} \mathrm{C}$ selama 7 menit. Selanjutnya telur dimasukkan ke dalam ruang inkubasi sampai menetas. Ulat dari masing-masing perlakuan dipelihara sampai menjadi kokon untuk mengetahui kualitas ulat dan kokon yang dihasilkan. Untuk menghindari adanya bias pemeliharaan, maka prosedur dan tempat pemeliharaan, serta jenis daun murbei dan volume pemberian pakan dibuat sama untuk semua ulat hasil penetasan. Parameter yang diamati meliputi:

a. Kualitas telur. Kualitas telur dinilai berdasarkan persentase penetasan (\%), yaitu perbandingan banyaknya telur yang menetas dengan jumlah total telur per induk dikali 100\%;

b. Kualitas ulat. Kualitas ulat dinilai berdasarkan rendemen pemeliharaan, diukur dengan membagi banyaknya kokon yang dihasilkan dengan jumlah ulat sutra yang dipelihara dikali $100 \%$; c. Kualitas kokon. Kualitas kokon dinilai berdasarkan beberapa parameter, yaitu persentase kokon normal, bobot kokon, bobot kulit kokon, dan persentase kulit kokon. Persentase kokon normal $(\mathrm{KN})$, diukur dengan cara membandingkan jumlah kokon normal dengan jumlah kokon keseluruhan kemudian dikalikan dengan $100 \%$.

Bobot kokon, merupakan bobot kokon dari rata-rata 50 butir sampel dalam satuan gram, diukur dengan menimbang bobot kokon seluruhnya yaitu kokon berikut pupa yang ada di dalamnya.

Bobot kulit kokon, diukur dengan menimbang kulit kokon, yaitu kokon setelah pupa yang ada didalamnya dikeluarkan.

Persentase kulit kokon (KK), diukur dengan membagi bobot kulit kokon dengan bobot kokon dikalikan 100\%.

\section{Analisis Data}

Data yang diperoleh dianalisis menggunakan sidik ragam untuk melihat pengaruh perlakuan terhadap berbagai parameter yang diuji. Data dianalisis dengan bantuan program statistika $J M P$ Start Statistics 8. Data yang menunjukkan perbedaan nyata diuji lebih lanjut dengan uji Tukey.

\section{HASIL DAN PEMBAHASAN}

\section{A. Hasil}

1. Kondisi hutan ideal dan faktanya

Hasil analisis ragam menunjukkan bahwa faktor galur ulat, penyimpanan, serta interaksi keduanya tidak berpengaruh pada parameter rendemen pemeliharaan, persentase kokon normal, dan rasio kulit kokon. Interaksi antara galur ulat dan faktor penyimpanan memberikan hasil yang nyata pada bobot kokon. Faktor galur ulat memberikan perbedaan yang nyata $(\mathrm{p}<0,05)$ pada rendemen pemeliharaan dan bobot kulit kokon, sedangkan faktor penyimpanan 


\section{Pengaruh Penyimpanan dan Waktu Penetasan Telur Terhadap Kualitas Bibit Ulat Sutra dan Kualitas Kokon Bombyx Mori L.}

Lincah Andadari dan Kuntadi

memberikan perbedaan yang nyata $(\mathrm{p}<0,05)$ pada persentase penetasan dan bobot kulit kokon (Tabel 1).

Tabel (Table) 1. Hasil analisis pengaruh perlakuan terhadap parameter penetasan, rendemen pemeliharaan, persentase kokon normal, bobot kokon, rasio kulit kokon, dan bobot kulit kokon (Result analysis of treatment effects on hatchability percentage, cocoon yield percentage, normal cocoon percentage, cocoon weight, shell weight, and shell ratio).

\begin{tabular}{|c|c|c|c|c|c|c|}
\hline $\begin{array}{c}\text { Sumber ragam } \\
\text { (Source of } \\
\text { variance) }\end{array}$ & $\begin{array}{c}\text { Persentase } \\
\text { Penetasan } \\
\text { (Hatchability } \\
\text { percentage) }\end{array}$ & $\begin{array}{c}\text { Rendemen } \\
\text { Pemeliharaan } \\
\text { (Cocoon yield } \\
\text { percentage) }\end{array}$ & $\begin{array}{c}\text { Persentase } \\
\text { kokon normal } \\
(\text { Normal } \\
\text { cocoon } \\
\text { percentage })\end{array}$ & $\begin{array}{l}\text { Bobot } \\
\text { kokon } \\
\text { (Cocoon } \\
\text { weight) }\end{array}$ & $\begin{array}{c}\text { Bobot } \\
\text { kulit } \\
\text { kokon } \\
\text { (Shell } \\
\text { weight) }\end{array}$ & $\begin{array}{l}\text { Rasio } \\
\text { kulit } \\
\text { kokon } \\
\text { (Shell } \\
\text { ratio) }\end{array}$ \\
\hline $\begin{array}{l}\text { A. Galur ulat } \\
\text { (Strain of } \\
\text { silkworm) }\end{array}$ & tn & $*$ & tn & $*$ & $*$ & $\operatorname{tn}$ \\
\hline $\begin{array}{l}\text { B. Penyimpanan } \\
\text { (Preservation) }\end{array}$ & $*$ & tn & $\operatorname{tn}$ & $*$ & $*$ & $\operatorname{tn}$ \\
\hline C. $A \times B$ & tn & tn & $\operatorname{tn}$ & $*$ & tn & tn \\
\hline
\end{tabular}

Hasil uji Tukey menunjukkan bahwa rata-rata persentase penetasan telur ulat sutra tidak berbeda nyata antara faktor penyimpanan cara $1\left(1\right.$ hari $25^{\circ} \mathrm{C}+69$ hari $\left.5^{\circ} \mathrm{C}\right)$ dengan cara $2\left(10\right.$ hari $25^{\circ} \mathrm{C}+60$ hari $5^{\circ} \mathrm{C}$ ), namun tidak berbeda nyata dengan perlakuan lainnya. Metode penyimpanan cara B2 $\left(10\right.$ hari $25^{\circ} \mathrm{C}+60$ hari pada suhu $\left.5^{\circ} \mathrm{C}\right)$ tidak berbeda nyata dengan penyimpanan cara $\mathrm{B} 3\left(20\right.$ hari $25^{\circ} \mathrm{C}+50$ hari $5^{\circ} \mathrm{C}$ ), namun berbeda nyata dengan perlakuan lainnya. Oleh karena itu, faktor yang terbaik untuk penyimpanan kedua jenis ulat sutra tersebut yaitu penyimpanan cara 1 yaitu selama 1 hari di ruang bersuhu $25^{\circ} \mathrm{C}+$ di refrigerator selama 69 hari pada suhu $5^{\circ} \mathrm{C}$ (Tabel 2). Data penetasan telur menunjukkan bahwa semakin pendek penyimpanan pada suhu ruang $25^{\circ} \mathrm{C}$ yang diikuti dengan semakin lama penyimpanan di tempat dingin pada suhu $5^{\circ} \mathrm{C}$ menghasilkan persentase penetasan semakin tinggi.

Saat terjadinya penetasan telur menunjukkan bahwa masa inkubasi telur berlainan tergantung kepada faktor penyimpanan. Metode penyimpanan cara $\mathrm{B} 1\left(1\right.$ hari $25^{\circ} \mathrm{C}+69$ hari $\left.5^{\circ} \mathrm{C}\right)$ menunjukkan telur menetas lebih cepat dan serempak, yaitu 10-12 hari. Pada penyimpanan cara $\mathrm{B} 4\left(40\right.$ hari $25^{\circ} \mathrm{C}+30$ hari $5^{\circ} \mathrm{C}$ ) ternyata masa inkubasi lebih lama (18-20 hari) dan tidak serempak sehingga persentase penetasannya rendah.

Tabel (Table) 2 Rerata persen penetasan telur pada empat metode penyimpanan (Mean percentage of eggs hatchability at four preservation methods).

\begin{tabular}{|c|c|}
\hline $\begin{array}{l}\text { Faktor penyimpanan } \\
\text { (Factor of preservation) }\end{array}$ & $\begin{array}{c}\text { Persentase penetasan (Hatchability } \\
\text { percentage) }(\%)\end{array}$ \\
\hline $\mathrm{B} 11$ hari/day $25^{\circ} \mathrm{C}+69$ hari $/$ days $5^{\circ} \mathrm{C}$ & $95,27 \mathrm{a}$ \\
\hline B2 10 hari/days $25^{\circ} \mathrm{C}+60$ hari/days $5^{\circ} \mathrm{C}$ & $89,32 \mathrm{ab}$ \\
\hline B3 20 hari/days $25^{\circ} \mathrm{C}+50$ hari/days $5^{\circ} \mathrm{C}$ & $82,79 \mathrm{~b}$ \\
\hline B4 40 hari/days $25^{\circ} \mathrm{C}+30$ hari/days $5^{\circ} \mathrm{C}$ & $62,80 \mathrm{c}$ \\
\hline
\end{tabular}



Tukey (The mean values followed by the same letter are not significantly different at $5 \%$ Tukey tests)

Hasil analisis uji lanjut menunjukkan bahwa faktor galur hibrid menghasilkan persentase rendemen pemeliharaan lebih tinggi dibandingkan galur murni, namun. semua faktor galur ulat sutra telah menghasilkan rendemen hasil kokon yang sama baiknya, yaitu rata-rata di atas $90 \%$ (Tabel 3).

Pada parameter kualitas kokon, terlihat adanya pengaruh interaksi faktor jenis ulat dengan faktor penyimpanan. Galur hibrid menghasilkan bobot kokon yang sama pada keempat teknik penyimpanan, sedangkan galur murni menghasilkan bobot kokon yang semakin rendah untuk penyimpanan pada suhu kamar (25oC) semakin lama (Tabel 4).
Meskipun demikian bobot kokon belum menunjukkan hasil maksimal karena bobot kokon bisa mencapai lebih dari 2 gram.

Hasil analisis bobot kulit kokon menunjukkan perbedaan yang nyata pada faktor galur ulat dan faktor cara penyimpanan (Tabel 5). Galur hibrid ulat sutra menghasilkan rata-rata bobot kulit kokon yang lebih tinggi daripada galur murni. Faktor penyimpanan cara B2 (10 hari $25^{\circ} \mathrm{C}+60$ hari $\left.5^{\circ} \mathrm{C}\right)$ dan cara $\mathrm{B} 3(20$ hari $25^{\circ} \mathrm{C}+50$ hari $5^{\circ} \mathrm{C}$ ) menghasilkan bobot kulit kokon yang tidak berbeda nyata, tetapi berbeda nyata dan lebih tinggi jika dibandingkan dengan dua cara penyimpanan lainnya (cara B1 dan B4).

Tabel (Table) 3.Rerata rendemen pemeliharaan pada dua jenis ulat dan empat cara penyimpanan (The mean percentage of cocoon yield at two strain of silkworms and four egg preservation methods)

\begin{tabular}{|c|c|c|}
\hline \multicolumn{2}{|l|}{ Faktor/Factor } & $\begin{array}{l}\text { men Pemeliharaan } \\
\text { coon yield) }(\%)\end{array}$ \\
\hline \multicolumn{3}{|l|}{ Galur ulat/Strain of silkworm } \\
\hline \multicolumn{2}{|l|}{804} & $95,19 \mathrm{~b}$ \\
\hline \multicolumn{2}{|l|}{8483} & 98,63 a \\
\hline \multicolumn{3}{|l|}{ Penyimpanan/Preservation } \\
\hline \multicolumn{2}{|l|}{ B1 1 hari/day $25^{\circ} \mathrm{C}+69$ hari/days $5^{\circ} \mathrm{C}$} & $95.50 \mathrm{a}$ \\
\hline \multicolumn{2}{|l|}{ B2 10 hari $/$ days $25^{\circ} \mathrm{C}+60$ hari $/$ days $5^{\circ} \mathrm{C}$} & $92.00 \mathrm{a}$ \\
\hline \multicolumn{2}{|l|}{ B3 20 hari/days $25^{\circ} \mathrm{C}+50$ hari/days $5^{\circ} \mathrm{C}$} & 90.63 a \\
\hline \multicolumn{2}{|l|}{ B4 40 hari/days $25^{\circ} \mathrm{C}+30$ hari/days $5^{\circ} \mathrm{C}$} & $89.88 \mathrm{a}$ \\
\hline \multicolumn{3}{|c|}{$\begin{array}{ll}\text { Keterangan (Remark): } & \begin{array}{l}\text { Nilai rerata diikuti dengan huruf yang sama tidak berbeda nyata pada taraf 5\% } \\
\text { (The mean values followed by the same letter are not significantly different at 5\%) }\end{array}\end{array}$} \\
\hline \multicolumn{3}{|c|}{$\begin{array}{l}\text { Tabel (Table) 4.Pengaruh interaksi antara jenis ulat dan penyimpanan terhadap bobot kokon } \\
\text { (The effect of interaction between strain of silkworm and eggs preservation } \\
\text { on cocoon weight) }\end{array}$} \\
\hline Galur ulat/Strain of silkworm & \multicolumn{2}{|c|}{ Bobot kokon (Cocoon weight) $(g)$} \\
\hline Penyimpanan/Preservation & 804 & 8483 \\
\hline $\mathrm{B} 11$ hari/day $25^{\circ} \mathrm{C}+69$ hari/days $5{ }^{\circ} \mathrm{C}$ & $1,923 \mathrm{a}$ & $1,885 \mathrm{ab}$ \\
\hline B2 10 hari/days $25^{\circ} \mathrm{C}+60$ hari $/$ days $5^{\circ} \mathrm{C}$ & $1,778 \mathrm{bcd}$ & $1,923 \mathrm{a}$ \\
\hline B3 20 hari/days $25^{\circ} \mathrm{C}+50$ hari $/$ days $5^{\circ} \mathrm{C}$ & $1.723 \mathrm{~cd}$ & $1,888 \mathrm{ab}$ \\
\hline B4 40 hari/days $25^{\circ} \mathrm{C}+30$ hari $/$ days $5^{\circ} \mathrm{C}$ & $1,650 \mathrm{~d}$ & $1,795 \mathrm{abc}$ \\
\hline
\end{tabular}




\section{Pengaruh Penyimpanan dan Waktu Penetasan Telur Terhadap Kualitas Bibit Ulat Sutra dan Kualitas Kokon Bombyx Mori L.}

Lincah Andadari dan Kuntadi

Keterangan (Remark) : $\quad$ Nilai dalam kolom yang diikuti dengan huruf yang sama tidak berbeda nyata pada taraf $5 \%$ (Values at the same column followed by the same letter are not significantly different at 5\%)

\section{B. Pembahasan}

Tata cara penyimpanan bibit ulat sutra untuk penggunaan jangka panjang telah banyak dikaji melalui penyimpanan telur (Anton, Mărghitaş, \& Dezmirean, 2015; Kumar \& Ponnuvel, 2007; Muthulakshmi \& Kamble, 2015), kokon (Shukla, Prasad, \& Upadhyay, 2014), bahkan ovarium (Banno et al., 2013). Prosedur penyimpanan dan penetasan telur paling banyak dipelajari dengan maksud untuk mendapatkan metode pengaturan waktu penggunaan telur dengan tetap mempertahankan viabilitas dan kualitas bibit dalam jangka pendek, menengah, dan panjang, baik untuk galur bibit yang secara alami mengalami fase diapaus (Singh, Reddy, Kumari, Angadi, \& Sivaprasad, 2015; Singh et al., 2014; Iizuka, Mase, Okada, \& Yamamoto, 2008; Rajanna et al., 2008) maupun yang tidak (Rajanna, Reddy, Harlapur, \& Basavaraja, 2011; Singh, Nirupama, \& Gangopadhyay, 2010; Kumaresan et al., 2004). Beberapa parameter yang biasa digunakan sebagai tolok ukur penilaian hasil uji coba adalah fekunditas, persentase penetasan, rendemen pemeliharaan (hasil kokon), dan kualitas kokon (Singh et al., 2015; Rajanna et al., 2008). Uji coba penyimpanan dan penetasan telur dari dua galur ulat sutra menggunakan metode satu tahap pendinginan (single step refrigeration) pada suhu $5^{\circ} \mathrm{C}$ memperlihatkan adanya pengaruh interaksi perlakuan galur ulat sutra dan cara penyimpanan hanya pada bobot kokon. Perlakuan ulat galur murni dan hibrid menunjukkan galur ulat berpengaruh terhadap rendemen pemeliharaan, sedangkan jangka waktu penyimpanan bibit selama 70 hari menunjukkan lama waktu pendinginan berpengaruh terhadap persentase penetasan telur dan bobot kulit kokon, tetapi tidak banyak berpengaruh kepada parameter yang lain.
Hasil penelitian mengindikasikan semakin pendek masa simpan telur di suhu kamar $\left(25^{\circ} \mathrm{C}\right)$ dan diikuti pendinginan pada suhu $5^{\circ} \mathrm{C}$ dengan jangka waktu yang lebih panjang maka semakin tinggi persentase penetasan yang didapat. Dari empat perlakuan lama waktu penyimpanan dingin, setidaknya terdapat satu jenis perlakuan yang mampu menghasilkan persentase penetasan sangat tinggi di atas $90 \%$. Perlakuan B1 dengan lama pendinginan 69 hari setelah penyimpanan suhu kamar 1 hari menghasilkan angka penetasan 95,27\%, sementara penyimpanan dingin 60 hari setelah disimpan pada temperatur kamar 10 hari hanya mencapai sekitar $89 \%$ dan penyimpanan telur dengan waktu pendinginan yang lebih singkat menghasilkan persentase penetasan yang lebih rendah lagi. Data tersebut menunjukkan bahwa, selain lama waktu penyimpanan telur, perlu penyimpanan dingin dengan waktu yang cukup agar menghasilkan angka penetasan yang baik. Dengan kata lain perbandingan antara lama penyimpanan dingin dan penyimpanan suhu kamar perlu mendapat perhatian karena sangat menentukan tingkat penetasan telur. Menurut Chen (2000) penetasan di atas 90\% dicapai setelah penyimpanan dingin minimal 55 hari dan sebelumnya disimpan pada temperatur kamar selama 18-26 hari. Hasil penelitian kami memberi petunjuk bahwa penggunaan metode satu tahap pendinginan dapat digunakan dalam penyimpanan telur untuk penggunaan/ penetasan 70 hari dengan jangka waktu penyimpanan dingin di atas 60 hari. Untuk jangka waktu penggunaan di atas 70 hari masih perlu kajian lebih lanjut mengingat penelitian Rajanna et al. (2008) memperlihatkan persentase penetasan yang semakin turun.

Perlakuan galur ulat berpengaruh terhadap rendemen pemeliharaan (Tabel 
2). Hibrid menunjukkan hasil rendemen pemeliharaan yang lebih tinggi, sesuai dengan hasil penelitian Andadari dan Sunarti (2015) yang menunjukkan kombinasi persilangan dengan induk betina 804 menghasilkan rendemen pemeliharaan terbaik dibandingkan kombinasi yang lain. Hibrid 8483 menggunakan indukan 804. Rendemen pemeliharaan tampaknya lebih ditentukan oleh galur ulat sutra. Meskipun berbeda nyata semua perlakuan menghasilkan rendemen pemeliharaan di atas $90 \%$ yang berarti cukup baik (Andadari et al., 2013) karena rendemen pemeliharaan sangat berpengaruh pada produksi kokon yang dihasilkan (Rahma, 2017).

Bobot kokon merupakan salah satu parameter yang digunakan dalam menguji kualitas kokon. Semakin tinggi bobot kokon yang dihasilkan kualitas kokonnya semakin baik (Nursita, 2012). Bobot kokon mempunyai korelasi positif dengan hasil kokon per boks (Andadari et al., 2013). Pada penelitian ini terdapat perbedaan yang nyata pada bobot kokon dan bobot kulit kokon antara galur murni dan hibrid. Meskipun interaksi perlakuan penyimpanan dan galur ulat sutra berpengaruh nyata pada bobot kokon, akan tetapi galur ulat lebih berperan menentukan bobot kokon dan bobot kulit kokon yang dihasilkan daripada perlakuan lama penyimpanan. Data pada Tabel 4 dan Tabel 5 menunjukkan bobot kokon dan bobot kulit kokon dari telur galur murni rata-rata lebih rendah dibandingkan ratarata bobot kokon dan bobot kulit kokon yang berasal dari telur jenis hibrid.

Bobot kulit kokon berhubungan dengan kandungan sutra yang dapat dimanfaatkan. Semakin besar bobot kulit kokon, maka semakin besar kandungan benang sutra. Kumar et al. (2011) mengemukakan bahwa bobot kulit kokon ditentukan oleh galur, jenis kelamin ulat yang dipelihara, kondisi pemeliharaan, dan pengokonan. Kedua tipe penyimpanan, yaitu $\mathrm{B} 2\left(10\right.$ hari $25^{\circ} \mathrm{C}+60$ hari $\left.5^{\circ} \mathrm{C}\right)$ dan $\mathrm{B} 3\left(20\right.$ hari $25^{\circ} \mathrm{C}+50$ hari $5^{\circ} \mathrm{C}$ ), menghasilkan bobot kulit kokon yang tinggi, sehingga untuk memaksimalkan hasil bobot kokon, jenis hibrid dapat disimpan pada ke dua tipe penyimpanan tersebut.

Berbeda dengan bobot kokon dan bobot kulit kokon yang menunjukkan adanya pengaruh perlakuan, data rasio kulit kokon secara statistik tidak memperlihatkan adanya perbedaan antar perlakuan, baik dari masing-masing faktor maupun interaksinya. Hal ini dimungkinkan karena pasca penetasan ulat dipelihara dalam kondisi pemeliharaan yang sama, sehingga faktor genetik dari masingmasing galur ulat tampaknya lebih dominan menentukan kualitas kokon yang dihasilkan daripada perlakuan penyimpanan. Secara umum, ulat sutra galur hibrid menunjukkan hasil yang lebih tinggi dibandingkan dengan galur murni. Galur hibrid menghasilkan kualitas kokon yang sama pada keempat teknik penyimpanan, namun penyimpanan cara B2 (10 hari $25^{\circ} \mathrm{C}+60$ hari $5^{\circ} \mathrm{C}$ ) cenderung menghasilkan kualitas kokon yang lebih baik dibandingan dengan cara penyimpanan yang lain. Sedangkan galur murni menghasilkan kualitas kokon yang tinggi pada penyimpanan selama 1 hari pada $25^{\circ} \mathrm{C}$ dan dilanjutkan selama 69 hari pada suhu $5^{\circ} \mathrm{C}$.

\section{KESIMPULAN DAN SARAN}

\section{A. Kesimpulan}

1. Galur ulat hibrid dapat diterapkan pada keempat teknik penyimpanan sedangkan galur murni akan menyamai produktivitas hibrid apabila disimpan pada kondisi 1 hari pada suhu $25^{\circ} \mathrm{C}$ dan dilanjutkan pada suhu $5^{\circ} \mathrm{C}$ selama 69 hari.

2. Penyimpanan pada suhu $25^{\circ} \mathrm{C}$ selama 10 hari dan dilanjutkan pada suhu $5^{\circ} \mathrm{C}$ selama 60 hari akan menghasilkan kualitas telur dan kualitas kokon yang lebih bagus. 


\section{Pengaruh Penyimpanan dan Waktu Penetasan Telur Terhadap Kualitas Bibit Ulat Sutra dan Kualitas Kokon Bombyx Mori L.}

Lincah Andadari dan Kuntadi

\section{B. Saran}

1. Telur ulat sutra dari galur murni yang akan digunakan saat berumur 70 hari sebaiknya menggunakan teknik penyimpanan pada temperatur $25^{\circ} \mathrm{C}$ selama 1 hari dilanjutkan penyimpanan dingin $\left(5^{\circ} \mathrm{C}\right)$ selama 69 hari dan untuk menetaskannya diberi perlakuan asam dengan berat jenis 1,094 pada temperatur $48^{\circ} \mathrm{C}$ selama 7 menit.

2. Untuk efisiensi biaya dan menghasilkan kualitas kokon yang tinggi, telur galur hibrid yang akan digunakan saat berumur 70 hari sebaiknya menggunakan teknik penyimpanan pada temperatur $25^{\circ} \mathrm{C}$ selama 10 hari dilanjutkan penyimpanan dingin $\left(5^{\circ} \mathrm{C}\right)$ selama 60 hari, kemudian diberi perlakuan asam dengan berat jenis 1,094 pada temperatur $48^{\circ} \mathrm{C}$ selama 7 menit.

\section{UCAPAN TERIMA KASIH}

Penelitian ini dibiayai melalui dana APBN dari DIPA Pusat Penelitian dan Pengembangan Hutan (P3H). Ucapan terimakasih penulis sampaikan kepada Tri Rahmawati dan Teknisi di Laboratorium Sutra Alam (Hermansari, Oting dan Ridwan) yang telah membantu dalam penelitian ini. Terimakasih juga kami tujukan untuk Dr. Kaomini yang telah memberikan masukan dalam penulisan naskah ini.

\section{DAFTAR PUSTAKA}

Abdelmegeed, S.M. (2016). Artificial hatching of monovoltine silkworm Bombyx mori L . Eggs by using hydr ${ }^{\circ} \mathrm{C}^{\circ}$ Chloric acid. J. Plant Prot. and Path., Mansoura Univ., 7(4), 237-240.

Anton, N., Mărghitaş, A., \& Dezmirean, D. (2015). Diapause storage temperature influence on silkworm larva hatching rate. Ecotoxicologie, Zootehnie Şi Tehnologii de Industrie
Alimntară, XIV(B), 341-348.

Andadari, L. \& Sunarti. 2015. Kualitas kokon hasil silangan antara ulat sutra (Bombyx mori L.) Ras Cina dan Ras Jepang. Jurnal Pemuliaan Tanaman Hutan. Vol. 9. No.1 Balai Besar Penelitian Bioteknologi dan Pemuliaan Tanaman Hutan.

Andadari, L., Pudjiono. S., Suwandi, \& Rahmawati, T. (2013). Budidaya murbei dan ulat sutra. FORDA PRESS. ISBN: 978-602-14274-6-0.

Banno, Y., Nagasaki, K., Tsukada, M., Minohara, Y., Banno, J., Nishikawa, K., _. Fujii, T. (2013). Development of a method for longterm preservation of Bombyx mori silkworm strains using frozen ovaries. CRYOBIOLOGY, xxx, 3-7. https://doi.org/10.1016/j.cryobiol.2 013.03.004

Chen, Y.Y. (2000). Practical techniques of acid-treatment to diapause eggs after refrigeration. Sericologia, 40(4), 563-569.

Hemmatabadi, R.N., Seidavi, A., \& Gharahveysi, S. (2016). A review on correlation, heritability and selection in silkworm breeding. Journal of Applied Animal Research, 44(1), 9-23. https:// doi.org/10.1080/09712119.2014.98 7289

lizuka, T., Mase, K., Okada, E., \& Yamamoto, T. (2008). Development a long-term storage method for diapause eggs in some hybrid races of Bombyx mori. Journal of Insect Biotechnology and Sericology, 77, 67-70.

Jingade, A.H., Babu, G.K.S., Lekha, G., Nair, C.V, Rao, A.A., \& Manjula, A. (2013). Silkworm (Bombyx mori) Cryopreservation: Embryonic Development as Revealed By ... CryoLetters, 34(1), 90-99. Retrieved from https://www. 
researchgate.net/publication/23568 1236

Kumar, R.S., \& Ponnuvel, K.M. (2007). Egg Diapause Induction in Multivoltine Silkworm Bombyx mori for Long-term Germplasm Preservation. Int. J. Indust. Entomol., 15(1), 1-7.

Kumaresan, L., Thangavelu, K., \& Sinha, R.K. (2004). Studies on leng-term presrvation of eggs of Indian tropical multivoltine silkworm (Bombyx mori L.) genetic resources. Int. J. Indust. Entomol., 9(1), 79-87.

Kumar, S,N., Singh, H., Saha, A.K. \& Bindroo, B.B. (2011). Development of bivoltine double hybrid of the silkworm, Bombyx Mori L. tolerant to high temperature and high humidity conditions of the tropics. Universal Journal of Environmental Research and Technology. eISSN 2249 0256, 1(4), 423-434.

Muthulakshmi, M., \& Kamble, C.K. (2015). Research article effect of long term egg preservation on morphological, reproductive and molecular characters of silkworm ( Bombyx mori L.) mutant genetic stocks. International Journal of Recent Scientific Research, 6(4), 3300-3305.

Nursita, I.W. (2012). Perbandingan produktivitas ulat sutra dari dua tempat pembibitan yang berbeda pada kondisi lingkungan pemeliharaan panas. Jurnal Ilmuilmu Peternakan 21(3), 11-17.

Rahma, F., Moerfiah., \& Andadari, L. (2017). Pertumbuhan dan kualitas kokon ulat sutra (Bombyx mori) dengan pemberian pakan daun murbei (Morus cathayana) dan daun murbei hibrid suli-01. Jurnal Unpak, 3(3). jom.unpak.ac.id/ index.php/biologi/article/view/947

Rahmathulla, V.K. (2012). Management of climatic factors for successful silkworm (Bombyx mori L.) crop and higher silk production: A review. Psyche, 2012(Article ID 121234), 1-12. https://doi.org/ $10.1155 / 2012 / 121234$

Rajanna, K.L., Raju, P.J., Prabhakar, C.J., \& Kamble, C.K. (2008). Preservation of Acid Treated Bivoltine Eggs in Silkworm Bombyx mori L . Int. J. Indust. Entomol., 17(2), 165-168.

Rajanna, K.L., Reddy, G.V, Harlapur, V.K., \& Basavaraja, H.K. (2011). Development of new cold storage preservation technology for cross breed (PM X CSR2) eggs of silkworm, Bombyx mori L. Sericologia, 51(1), 77-85.

Sarkar, B.N., Sarmah, M.C., Dutta, P., \& Dutta, K. (2012). Embryo isolation and egg preservation technology of eri silkworm Samia ricini (Donovan) (Lepidoptera: Saturniiedae). Munis Entomolgy \& Zoology, 7(2), 792-797.

Shukla, S., Prasad, S., \& Upadhyay, V.B. (2014).

Biotechnological importance of $\quad \mathrm{c}^{\circ} \mathrm{C}^{\circ} \mathrm{Coon}$ refrigeration on the pupal performance of multivoltine mulberry silkworm ( Bombyx mori L.). Pinnacle Biotechnology, 1(1), 4-9.

Singh, R., Nirupama, R., \& Gangopadhyay, D. (2010). Effect of refrigeration of non-diapause eggs of the mulberry silkworm, Bombyx mori L. Sericologia, 50(1), 129-132.

Singh, R., Reddy, G.V., Rajanna, K.L., Vijayakumari, K.M., Angadi, B.S., \& Sivaprasad, V. (2014). Development of different egg preservation schedules for "Barbat", an univoltine race of the mullbery silkworm, Bombyx mori L. Munis Entomolgy \& Zoology, 9(1), 521524.

Singh, R., Reddy, G.V, Kumari, K.M.V, 
Angadi, B.S., \& Sivaprasad, V. (2015). Evaluation of egg preservation schedules for bivoltine breeds of the silkworm mulberry, Bombyx mori L. Munis Entomolgy \& Zoology, 10(1), 241-245.

Singh, T., \& Saratchandra, B. (2004). Principles and Techniques of Silworm Seed Production. New Delhi: Discovery Publishing House.

Singh, T., Singh, P.K., \& Sahaf, K.A. (2013). Egg Diapause and Metabolic Modulations during Embryonic Development in the Silkworm, Bombyx mori L.
(Lepidoptera: Bombycidae ). Annals of Biological Research, 4(1), 12-21.

Sall, J., Creighton, L., \& Lehman, A. (2005). JMP start statistic 2nd. A Guide to statistics and data analysis using JMP and JMP IN software.

Yamamoto, T., Mase, K., \& Sawada, H. (2013). Diapause Prevention Effect of Bombyx mori by Dimethyl Sulfoxide. PLoS ONE, 8(5), e64124. https://doi.org/10.1371/journal.pon e.0064124. 